\title{
EI nuevo Coronavirus y la pandemia del Covid-19
}

\author{
The new Coronavirus and Covid-19 pandemic
}

Ciro Maguiña Vargas ${ }^{1, a ; 2, b}$, Rosy Gastelo Acosta ${ }^{3, c}$, Arly Tequen Bernilla ${ }^{3, c}$

\section{INTRODUCCIÓN}

La actual pandemia de Covid-19, producida por una cepa mutante de coronavirus el SARS-CoV-2, ha generado en todo el mundo, en el siglo 21, una severa crisis económica, social y de salud, nunca antes vista. Se inició en China a fines de diciembre 2019, en la provincia de Hubei (cuidad Wuhan) donde se reportó un grupo de 27 casos de neumonía de etiología desconocida, con siete pacientes graves. El primer caso fue descrito el 8 de diciembre 2019 (1), el 7 de enero 2020 el Ministerio de sanidad de China identifica un nuevo coronavirus (nCoV) como posible etiología (1), para el 24 enero en China se habían reportado 835 casos (534 de Hubei) y con el correr de las semanas se extendió a otras partes de China (2). El 13 de enero se reportó el primer caso en Tailandia (3), el 19 de enero en Corea del Sur (4), y luego en numerosos países de mundo, debido a lo cual la Organización Mundial de la Salud (OMS), declara desde marzo 2020 como una nueva pandemia mundial (5). En China todavía no se conoce el origen del virus, aunque se atribuye al pangolín, mamífero usado como alimento (6).

El virus SARS-CoV-2 es muy contagioso y se transmite rápidamente de persona a persona a través de la tos o secreciones respiratorias, y por contactos cercanos; las gotas respiratorias de más de cinco micras, son capaces de transmitirse a una distancia de hasta dos metros, y las manos o los fómites contaminados con estás secreciones seguido del contacto con la mucosa de la boca, nariz u ojos (7).
Debido a que no hubo un aislamiento social a tiempo en China y luego en Italia y España, la enfermedad se esparció rápidamente a muchos países porque es muy contagiosa.

Este nuevo virus tiene predilección por el árbol respiratorio, una vez que penetra genera una respuesta inmune anormal de tipo inflamatorio con incremento de citoquinas, lo que agrava al paciente y causa daño multiorgánico.

Es de la familia de los viejos virus coronavirus, dos de cuyas cepas antiguas causan la gripe común, pero en el 2003 surgió la primera mutación, el SARS que se inició en China, con más de 8460 pacientes en 27 países y una letalidad de $10 \%$ (8), y luego en el año 2012 apareció otra cepa mutante de coronavirus en Arabia Saudita, el MERS-CoV, con más de 2499 enfermos y una letalidad del 37\% (9).

Está revisión busca actualizar aspectos básicos y fundamentales del nuevo coronavirus, el Covid-19, su epidemiología, clínica y terapia.

\section{Estructura viral}

Son virus envueltos, pleomórficos o esféricos, que presentanARNcomogenomaycuyotamañooscilaentre los 80 a $120 \mathrm{~nm}$ de diámetro. Superficialmente pueden observarse proyecciones de la glicoproteína spike (S), $\mathrm{y}$ al igual que la mayoría de los betacoronavirus posee dímeros de proteínas hemaglutinina-esterasa (HE). La

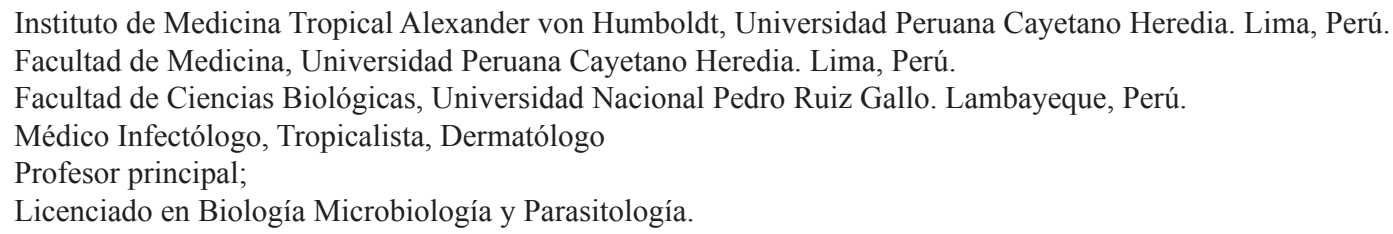


envoltura viral consta de dos proteínas que resaltan: la proteína $\mathrm{M}$ y la proteína $\mathrm{E}$, siendo la primera la más abundante, mientras que la segunda se caracteriza por su carácter hidrofóbico; ambas proteínas se encuentran fusionadas con membranas lipídicas obtenidas de la célula hospedera. El genoma, está constituido por ARN de cadena simple, no segmentado y de polaridad positiva cargado con aproximadamente entre 27 a 32 Kilobases, las cuales codifican para 16 proteínas no estructurales; para evitar la desintegración del genoma, el ARN se encuentra unido a otra proteína estructural conocida como la nucleoproteína (Proteína N) (figura $1)$.

\section{Tipos de coronavirus}

Pertenecientes al orden Nidovirales y a la familia Coronaviridae, estos virus envueltos de tipo ARN se distinguen en 4 géneros: alfa, beta, delta y gamma; siendo los dos primeros quienes infectan a los humanos, provocando enfermedades que van desde un resfrío leve hasta infecciones severas como el MERS (9), y el SARS causantes de miles de muertes. De los siete coronavirus que afectan a humanos $(\mathrm{HCoV})$, cuatro son endémicos en todo el mundo y generan síntomas de resfrío, siendo los tipos 229E y OC43 los responsables del resfrío común, mientras que los tipos NL63 y HKU1 también se le asocian a problemas respiratorios. En algunos casos pueden producir infección en vías respiratorias inferiores, incluso neumonía en pacientes vulnerables, adultos mayores o personas inmunocomprometidas.

\section{Epidemiología y clínica}

Hasta el 14 de abril del 2020, fueron confirmados en el mundo más de 1792000 casos positivos, más de 110000 personas fallecieron, y más de 412000 pacientes se han recuperado de la enfermedad, según los datos de la Universidad Johns Hopkins (10).

El 11 de abril, Estados Unidos se convirtió en el país más afectado por el coronavirus, fueron registrados 530200 casos confirmados y 20614 muertes (11). En total, son cinco los países con más de 100000 casos positivos. A EE.UU., le sigue España (163 027 casos), Italia (152 271 casos), Francia (130 730 casos) y Alemania (125452 casos) (12). China cuenta con el total 83134 casos.

En cuanto a los fallecidos, detrás de EE.UU. se encuentran Italia (19 468 decesos), España (16 972 decesos), Francia (13 832 decesos), Reino Unido (9 875 decesos) y China con 3343 decesos (13).

En América Latina, la nación más afectada es Brasil con 20984 casos positivos y 1141 muertes (14); en Perú se tienen 10303 casos y 230 muertos (15).

\section{La naturaleza del virus y la enfermedad}

El nuevo coronavirus repite casi el $80 \%$ de la secuencia genética de su predecesor SARS-CoV, y al igual que otros coronavirus muta de patogenia.

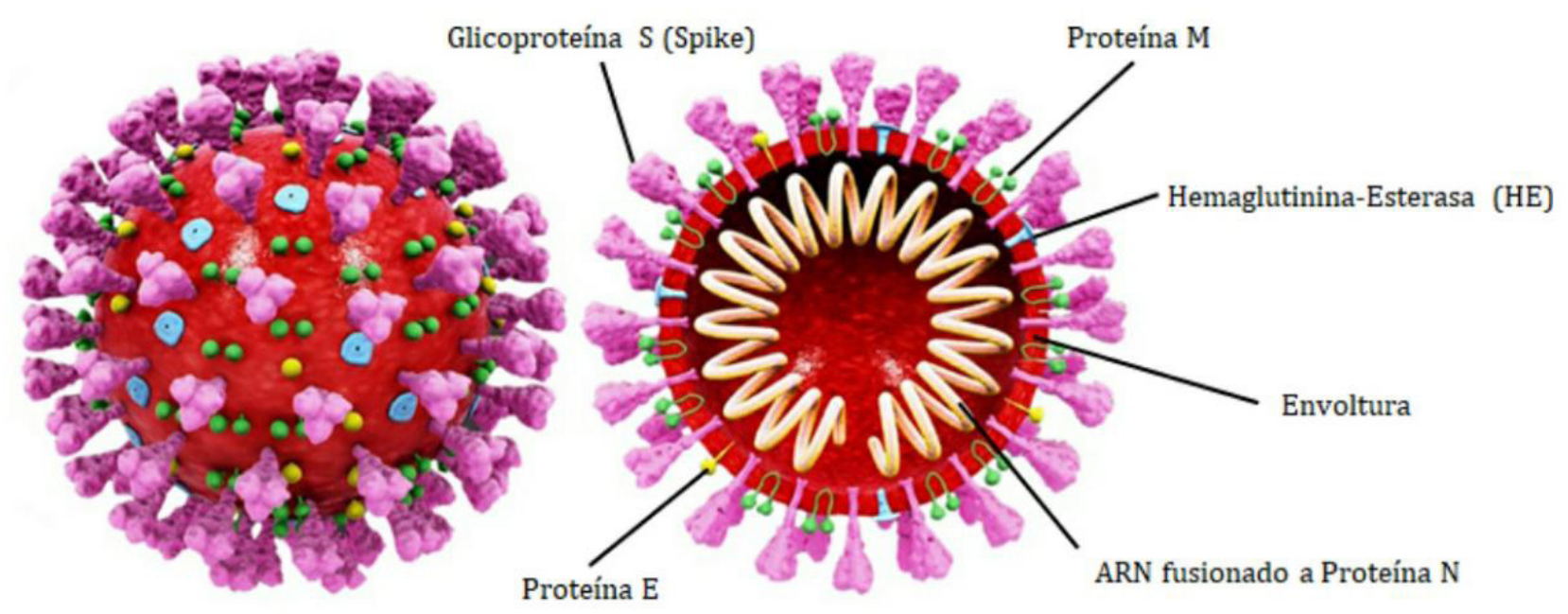

Figura 1. Estructura del coronavirus.

En la parte central del virus se muestra el genoma ARN ligado a la nucleoproteína $(\mathrm{N})$; en la zona periférica encontramos los trímeros de la glicoproteína $\mathrm{S}$, así como los dímeros de $\mathrm{HE}$, acompañados de las proteínas de membrana (M) y las proteínas de envoltura $(\mathrm{E})$. 
Los coronavirus expresan glucoproteínas transmembrana (proteínas de "pico") que permiten que el virus se adhiera y entre en la célula objetivo. Las proteínas de pico en el SARS-CoV-2 comparten muchas similitudes con las del SARS-CoV y se unen a los receptores de la enzima convertidora de angiotensina 2 de superficie (ACE2) (16). La proteína espiga del SARS-CoV-2 parece unirse a ACE2 con mayor afinidad que el SARS-CoV, lo que puede explicar su mayor transmisibilidad (17).

ACE2 se expresa predominantemente en los neumocitos tipo II, pero también en las células epiteliales del tracto respiratorio superior y los enterocitos del intestino delgado (18). La replicación viral de ARN ocurre dentro de la célula objetivo, utilizando ARN polimerasa dependiente de ARN (rdRp) (19).

La principal vía de trasmisión es la respiratoria, a través de la tos y estornudos, se ha detectado en las heces pero en poca cantidad, de ahí que las medidas de protección contemplan el uso de mascarillas, la higiene frecuente de manos con agua y jabón, a lo que se han sumado otras medidas preventivas adoptadas en muchos países, como la cuarentena y el distanciamiento social. La gran mayoría de los afectados se recuperan pero debido a que se trata de una nueva enfermedad no se conoce el estado de inmunidad. Se ha reportado que algunos pacientes en China dados de alta, siguen siendo positivos hasta 14 días posteriores.

\section{CLINICA}

El periodo de incubación se estimó entre 4 a 7 días, pero el $95 \%$ de los casos fue de 12 días, sin embargo, basados en otras estudios de casos de Europa, podría ser de 2 a 14 días.

La gran mayoría (80\%) de los casos son asintomáticos (pueden ser contagiosos) o tienen cuadros leves con malestar general y tos ligera, en tanto que el 15 por ciento hace un cuadro moderado con fiebre, tos seca persistente, fatiga, sin neumonía, y el 5 por ciento hacen cuadros severos, caracterizados por fiebre constante, tos, disnea severa, debido especialmente a la neumonía viral; daño cardiovascular, falla multiorgánica, y pueden fallecer entre 3 a $4 \%$ de los afectados.

\section{Fases de evolución}

En la primera semana(primera fase), el test de RTPCR nasofaríngea es positiva, y los anticuerpos (IgM,
IgG) son generalmente negativos; en cambio en la denominada fase dos (denominada pulmonar), que se inicia a partir del día al 15, es la fase donde se complica con neumonía, presentándose signos de consolidación bilateral distribución periférica). RT-PCR positiva en vías bajas a través del lavado broncoalveolar, la serología IgM/IgG comienza a ser positiva a partir del 6 día. La tercera fase (inflamatoria), ocurre a partir del día 10 a 15 , no se presenta en todos los casos, y cuando ello sucede, se da especialmente en mayores de 65 años y pacientes inmunodeprimidos o con otros factores de riesgo, produciéndose una desregulación con una respuesta inflamatoria exacerbada. En autopsias de algunos pacientes fallecidos en Italia, se vio que algunos presentaban trombosis venosas en diversas regiones como el pulmón y miembros inferiores.

\section{Evolución}

Normalmente el COVID-19 se presenta de forma leve o moderada y en una minoría, la forma grave (fiebre alta, $>30$ respiraciones/minuto, $\mathrm{SpO}_{2}<93 \%$, $\mathrm{FiO}_{2}>300$ ), la mortalidad en UCI en Wuhan fue de 61 por ciento (20).

Entre los síntomas observados en los pacientes peruanos destacan: la tos seca, dolor de garganta, cansancio y fiebre. Entre las características de 138 pacientes hospitalizados según la serie de Wang, la media de edad fue de 56 años, 75 varones, 46,4\% tenían alguna comorbilidad: $31,2 \%$ hipertensión arterial, $14,5 \%$ enfermedad cardiovascular, $10 \%$ diabetes mellitus, $7 \%$ neoplasia, 3\% enfermedad pulmonar obstructiva crónica (EPOC), en este estudio se contagiaron 40 miembros de los equipos de salud, siendo los síntomas más frecuentes: fiebre, tos, fatiga, astenia, anorexia, mialgias, disnea, el $1-10 \%$ tuvo diarrea y náuseas (21).

De las complicaciones en 99 pacientes hospitalizados de la serie de Chen N. (22), en China, 23 pasaron a UCI; 17 con SDRA, tres falla renal, ocho daño pulmonar agudo, cuatro choque séptico, uno neumonía pos ventilación; 11 de ellos fallecieron, $1 \%$ tuvo infección bacteriana secundaria.

\section{Mortalidad}

Los datos de Chi de los CDC sugieren una tasa de letalidad de 0,25-3\% (23). Las estimaciones varían según la ubicación de la enfermedad: van desde 1,17\% en Corea del Sur (24), 2,3\% en China (25), a 7,2\% en Italia (26). Las tasas de letalidad pueden ser más 
altas en los epicentros de la enfermedad debido a la falla del sistema que conduce a una mayor mortalidad o recursos reducidos para emprender programas de detección de pacientes ambulatorios (27).

Las estimaciones de mortalidad también pueden estar influenciadas por: datos demográficos de la población (Italia tiene una distribución de edad mayor que China), las diferencias en los programas de detección, como arriba, pueden subestimar el denominador y sobreestimar las tasas de mortalidad si no se prueban los casos leves.

\section{Factores de riesgo para la gravedad de la enfermedad y la mortalidad}

En cualquier edad se puede desarrollar una insuficiencia respiratoria severa, la mortalidad se relaciona con la edad con la mayor mortalidad 14$20 \%$ en $\geq 80$ años, menos niños tienden a sufrir enfermedades graves $(5,2 \%)$ o enfermedades críticas $(0,2 \%)(28)$.

Hasta marzo de 2020, no se reportaron muertes directamente por COVID en niños $<9$ años, sin embargo, ahora hay informes emergentes de muertes de niños, en los medios de comunicación (29), la tasa de letalidad es aproximadamente del $50 \%$ en casos críticos (25). La presencia de enfermedad coexistente es más común en pacientes con enfermedad grave, que incluye: Enfermedad cardiovascular, diabetes, enfermedad respiratoria crónica, hipertensión y cáncer (30). En Italia, de los que murieron, el 0,8\% no tenía enfermedad asociada, el $25,1 \%$ tenía una sola enfermedad, el 25,6\% tenía dos enfermedades, el 48,5\% tenía tres o más enfermedades (26), la población pediátrica desarrolla formas muy leves con riesgo muy bajo de fallecer; hasta el 14 de abril de 2020, solo se ha informado de un pequeño número de muertes pediátricas en todo el mundo en asociación con la infección por SARS-CoV-2.

Las tasas de transmisión vertical parecen bajas (como con el SARS-CoV) (22,31). La infección por SARS-CoV-2 no parece estar asociada con una mayor tasa de resultados adversos maternos, a diferencia de la pandemia de gripe H1N1 en la que las embarazadas estaban sobre-representadas en la mortalidad (32). Existe poca evidencia directa sobre el impacto de la infección por COVID-19 en pacientes inmunocomprometidos.

\section{Laboratorio}

La mayoría de las pruebas que existen son las que detectan anticuerpos ( $\operatorname{IgM}$ e $\operatorname{IgG}$ ), son reactivas a partir del séptimo día de infección, estás usan diversas técnicas como las de inmunocromatografía.

El test de anticuerpos $\operatorname{IgM} / \operatorname{IgG}$ se va haciendo progresivamente positivo con el paso de los días desde el inicio de los síntomas, siendo positivo a partir del $7^{\circ}$ día en el $50 \%$ de los pacientes, en el $10^{\circ}$ día en el $70 \%$ y en el $14^{\circ}$ día desde el inicio de los síntomas en el $100 \%$ de los pacientes.

Las mejores pruebas son las moleculares, especialmente la RT_PCR cuya sensibilidad varía según el área, siendo de $93 \%$ en muestras de lavado bronco alveolar, en esputo $72 \%$, en hisopado faríngeo $32 \%$, y nasal $63 \%$, por mencionar algunos. Dentro de estos métodos moleculares tenemos al sistema GeneXpert, el cual se ha implementado para la detección de SARS-CoV-2; la prueba proporciona una identificación rápida del coronavirus pandémico en aproximadamente 45 minutos, tomando menos de un minuto de preparación de la muestra. La rapidez de la prueba se considera una gran ventaja para la toma de decisiones en el tratamiento del paciente.

Con respecto a otros métodos complementarios podemos ver que en el laboratorio, el hemograma generalmente es normal aunque en algunos casos hay leucopenia y linfopenia. En pacientes hospitalizados puede haber elevación del dímero $\mathrm{D}$, prolongación del tiempo de protrombina, ferritina y DHL. Se ha descrito en pacientes de UCI elevación de troponina hasta en $31 \%$.

Se tienen marcadores de mal pronóstico, el más precoz, el aumento de ferritina (a partir del $4^{\circ}$ día), el dímero $\mathrm{D}$ después de la primera semana y va progresivamente aumentando con los días en los que no sobreviven, otros test como proteína $\mathrm{C}$ reactiva (PCR), troponina, LDH, IL-6 se elevan a partir del décimo tercer día, la procalcitonina se eleva si hay coinfeccion bacteriana asociada (33).

La tomografía de tórax puede ser normal en el 18\% de los casos no severos, típicamente es el compromiso basal periférico bilateral, y el derrame pleural es poco frecuente (menos del 5\%). 


\section{TERAPIA}

Con respecto al abordaje terapéutico se puede señalar que el manejo es básicamente sintomático y de sostén, no hay droga antiviral efectiva, ni cura alguna; se han investigado varias drogas tanto in vitro como in vivo en varios ensayos, con diversos resultados, algunos eficaces y otros no, entre ellos se tiene al Lopinavir/ritonavir, Remdesivir, favipiravir, azitromicina, interferón, cloroquina/hidroxicloroquina, ivermectina, nitoxazanida, doxiciclina, tocilizumab, sarilumab, siltuximab, bevacizumad, plasma de convalecientes, ozono, células madre, oxido nítrico, etc (34).

De todas ellas en el Perú se ha recomendado el uso de algunas medicinas de manera individual y con el consentimiento informado únicamente para pacientes con enfermedad leve con ambulatorios con factores de riesgo (diabetes mellitus, hipertensión, etc.) y en hospitalizados (35).

De las nuevas drogas se tiene al Remdesivir, es un pro fármaco de nucleótidos metabolizado a un análogo de trifosfato de adenosina, que inhibe la ARN polimerasa dependiente de ARN viral, causando la terminación prematura de la transcripción de ARN. Remdesivir es un inhibidor del RNA, en estudios en fase I se ha indicado una dosis de $200 \mathrm{mg} \mathrm{IV} / 24$ horas y luego $100 \mathrm{mg}$ IV/24 h durante 5-10 días.

La cloroquina actúa inhibiendo el receptor que necesita el virus para penetrar en las células (33), en la última guía del MINSA, abril 2020 (36), se ha sugerido en pacientes con Covid 19, el uso de fosfato de cloroquina $500 \mathrm{mg}$ cada 8 horas (VO) por 7 a 10 días, o hidroxicloroquina, a dosis de 200 cada 8 horas (VO) por 7 a 10 días. Otro esquema es la ivermectina a una dosis de 1 gota $(200 \mu \mathrm{g}) / \mathrm{kg} / \mathrm{dí}$.

Además existen estudios en fase II y III, donde se ha usado Tocilizumab o Siltuximab, que son inhibidores de la interleuquina 6 (IL-6) (Citoquina) a dosis de 8 $\mathrm{mg} / \mathrm{kg}$ de peso (mayor de $80 \mathrm{~kg}$ ) (33), la primera dosis de $600 \mathrm{mg}$ vía EV y una $2^{\mathrm{a}}$ dosis a las 12 horas; en pacientes con peso $<80 \mathrm{~kg}$, la primera dosis es $400 \mathrm{mg}$ EV y luego una segunda dosis a las 12 horas (en casos excepcionales, una tercera dosis); tocilizumab tiene una vida media entre 7 y 14 días. Entre sus principales efectos secundarios se describen, reactivación infecciones latentes (tuberculosis), diverticulitis complicada, en la fase III se pueden añadir corticoides para bajar la respuesta inflamatoria, pero nunca en la fase I que agravaría la infección vírica (33).

\section{CONCLUSIONES}

El nuevo virus SARS-Cov2, ha causado una severa pandemia a nivel mundial, desatando pánico y alarma universal ,ha generado colapso del sistema sanitario en muchas regiones del planeta, por ser muy contagioso, causando miles de muertes especialmente en adultos mayores con comorbilidades como diabetes mellitus o hipertensión arterial. De los órganos, el sistema respiratorio es el más afectado, pero puede afectar a cualquier órgano del ser humano. Hasta la fecha no existe terapia específica ni vacuna. La mejor forma de prevenirlo es con la cuarentena, higiene con frecuente lavado de manos y la aplicación del distanciamiento social.

\section{Correspondencia:}

Ciro Maguiña

Correo electrónico: ciro.maguina@upch.pe

\section{REFERENCIAS BIBLIOGRÁFICAS}

1. Ministerio de Sanidad. Actualización $\mathrm{n}^{0} 13$. Neumonía por nuevo coronavirus (2019-nCoV) en Wuhan, provincia de Hubei, (China). Madrid: Ministerio de Sanidad; 2020. (Citado el 15 de abril del 2020). Disponible en: https://www.mscbs.gob. es/profesionales/saludPublica/ccayes/ alertas Actual/nCov-China/documentos/ Actualizacion_13_2019-nCoV_China.pdf

2. Organización Panamericana de la Salud. Consideraciones de la Organización Panamericana de la Salud con respecto a la propagación del nuevo coronavirus emergente. Washington DC: Organización Panamericana de la Salud; 2020.

(Citado el 15 de abril del 2020). Disponible en: https://www.paho.org/bol/index.php?option $=$ com docman\&view =download \&alias $=153$ revisada-consideraciones-de-1a-opsncov-china-final\&category_slug=technicaldocumentation\&Itemid $=1094$

3. Organización Mundial de la Salud. Nuevo coronavirus -Tailandia (procedente de China). Ginebra: Organización Mundial de la Salud; 2020. (Citado el 15 de abril del 2020). Disponible en: http://www9.who.int/csr/don/14-january-2020novel-coronavirus-thailand/es/

4. Organización Mundial de la Salud. Nuevo coronavirus - República de Corea (procedente de China) Ginebra: Organización Mundial de la Salud; 2020. (Citado el 15 de abril del 2020). Disponible 
en: https://www.who.int/csr/don/21-january-2020novel-oronavirus-republic-of-korea-ex-china/es/

5. Organización Mundial de la Salud. Alocución de apertura del Director General de la OMS en la rueda de prensa sobre la COVID-19 celebrada el 11 de marzo de 2020. Ginebra: Organización Mundial de la Salud; 2020. (Citado el 15 de abril del 2020). Disponible en: https://www.who.int/es/ $\mathrm{dg} / \mathrm{speeches/detail/who-director-general-s-}$ opening-remarks-at-the-media-briefing-on-covid19---11-march-2020

6. Briggs H. Coronavirus: cómo se estrecha el cerco sobre el pangolín como probable transmisor del patógeno que causa el covid-19: Londres: BBC; 27 de marzo del 2020. (Citado el 15 de abril del 2020). Disponible en: https://www.bbc. com/mundo/noticias-52066430

7. Hung LS. The SARS epidemic in Hong Kong: what lessons have we learned? J R Soc Med. 2003; 96(8):374-8. doi: 10.1258/jrsm.96.8.374

8. Thompson L. Inicio de una nueva epidemia, SARS. Rev Med Hered. 2003; 14(2):49.

9. BMJ Best Practice. Visión general de los coronavirus. Londres: BMJ Publishing Group; 2018. (Citado el 15 de abril del 2020). Disponible en: https://bestpractice.bmj.com/topics/eses/3000165/

10. Wish-TV. ISDH: 13 muertes más de COVID-19; estado cercano a 8,000 casos positivos. Indianapolis: Wish-TV; 2020. (Citado el 15 de abril del 2020). Disponible en: https://www.wishtv. com/news/local-news/isdh-13-more-covid-19deaths-state-approaching-8000-positive-cases/

11. Redacción UH. EE.UU. supera a Italia como el país con más fallecidos por COVID-19. San Salvador: Última Hora SV; 12 de abril 2020. (Citado el 15 de abril del 2020). Disponible en: http://ultimahora.sv/ee-uu-supera-a-italia-comoel-pais-con-mas-fallecidos-por-covid-19/

12. Reforma. Panorama al día: Covid-19. Ciudad de México: Seguridad en América; 12 de abril del 2020. (Citado el 15 de abril del 2020). Disponible en: https://www.seguridadenamerica.com.mx/ noticias/articulos/24470/panorama-al-diacovid-19

13.TV-Novosti. Qué se sabe sobre el coronavirus un mes después de que la OMS declarara el brote como pandemia. Moscu: TV-Novosti; 12 abril 2020. (Citado el 15 de abril del 2020). Disponible en: https://actualidad.rt.com/actualidad/349662que-se-sabe-coronavirus-metodos-tratamiento

14. Statista. Número de casos confirmados de nuevos coronavirus (COVID-19) en Brasil al 14 de abril de
2020, por estado. Statista; 2020. (Citado el 15 de abril del 2020). Disponible en: https://www. statista.com/statistics/1103791/brazil-coronaviruscases-state/

15. Ministerio de Salud. Minsa: Casos confirmados por coronavirus COVID-19 ascienden a 10303 en el Perú (Comunicado $\mathrm{N}^{\circ}$ 65). Lima: Ministerio de Salud; 2020. (Citado el 15 de abril del 2020). Disponible en: https://www.gob.pe/institucion/ minsa/noticias/112670-minsa-casos-confirmadospor-coronavirus-covid-19-ascienden-a-10-303-enel-peru-comunicado-n-65

16.Zhang C, Wu Z, Li JW, Zao H, Wang G. Cytokine Release Syndrome in Severe COVID-19: Interleukin-6 Receptor Antagonist Tocilizumab May Be the Key to Reduce Mortality. Int J Antimicrob Agents. 2020; 55(5):105954. doi: 10.1016/j.ijantimicag.2020.105954

17. Walls A, Park YJ, Tortorici MA, Wall A, McGuire A, Veesler D. Structure, Function, and Antigenicity of the SARS-CoV-2 Spike Glycoprotein. Cell. 2020; 181(2):281-292.e6. doi: 10.1016/j.cell.2020.02. 058.

18. Hamming I, Timens W, Bulthuis M, Lely A,Navis $\mathrm{G}$, van Goor H. Tissue Distribution of ACE2 Protein, the Functional Receptor for SARS Coronavirus. A First Step in Understanding SARS Pathogenesis. J Pathol. 2004; 203(2):631-7. doi: 10.1002/ path. 1570

19.Lung J, Lin Y, Yao-Hsu Yang YH, et al. The potential chemical structure of anti-SARS-CoV-2 RNA-dependent RNA polymerase. J Med Virol. 2020; 92(6):693-697. DOI: 10.1002/jmv.25761

20. Yang $\mathrm{X}, \mathrm{Yu} \mathrm{Y,Xu} \mathrm{J}$, et al. Clinical course and outcomes of critically ill patients with SARSCoV-2 pneumonia in Wuhan, China: a singlecentered, retrospective, observational study. The Lancet Respiratory Medicine. 2020; 20:30079-5 DOI: $\quad$ https://doi.org/10.1016/S2213-2600(20) 30079-5

21. Wang D, Hu B, Hu C, et al. Clinical Characteristics of 138 Hospitalized Patients with 2019 Novel Coronavirus-Infected Pneumonia in Wuhan, China. JAMA. 2020: 2020:201585. doi: 10.1001/ jama.2020.1585

22. Chen N, Zhou M, Xuan Dong X, et al. Epidemiological and Clinical Characteristics of 99 Cases of 2019 Novel Coronavirus Pneumonia in Wuhan, China: A Descriptive Study. Lancet. 2020; 395(10223): 507-513. doi: 10.1016/S01406736(20)30211-7

23. Wilson N, Kvalsvig A, Telfar-Barnard L, Baker M. Case-Fatality Risk Estimates for COVID-19 
Calculated by Using a Lag Time for Fatality. Emerg Infect Dis. 2020; 26(6):1339-1441. doi: 10.3201/ eid2606.200320

24. INFOBAE. Corea del Sur experimentó un aumento de los casos por coronavirus y cifró en 100 los nuevos contagios. Buenos Aires: INFOBAE; 20 de marzo del 2020. (Citado el 15 de abril de 2020). Disponible en: https://www.infobae.com/america/ mundo/2020/03/25/corea-del-sur-experimentoun-aumento-de-los-casos-por-coronavirus-y-cifroen-100-los-nuevos-contagios/

25. Wu Z, McGoogan J. Characteristics of and Important Lessons from the Coronavirus Disease 2019 (COVID-19) Outbreak in China: Summary of a Report of 72314 Cases from the Chinese Center for Disease Control and Prevention. JAMA. 2020; 323(13):1239-1242. doi:10.1001/jama.2020.2648

26. Onder G, Rezza G, Brusaferro S. Case-fatality rate and characteristics of patients dying in relation to COVID-19 in Italy. JAMA. 2020; 323(18):17751776. doi:10.1001/jama.2020.4683

27. Chowell G, Mizumoto K. The COVID-19 Pandemic in the USA: What Might We Expect? Lancet. 2020; 395(10230):1093-1094. doi: 10.1016/S0140-6736(20)30743-1

28. Ludvigsson J. Systematic review of COVID-19 in children shows milder cases and a better prognosis than adults. Acta Paediatrica. 2020; 0:118. DOI: $10.1111 /$ apa. 15270

29. Sibthorpe C. Coronavirus: Newborn baby becomes 'world's youngest COVID-19 victim'. Londres: Sky News; 2 de abril del 2020. (Citado el 15 de abril del 2020). Disponible en: https://news.sky. com/story/coronavirus-newborn-baby-becomesworlds-youngest-covid-19-victim-11967230
30.Li Q, Guan X, Su P, etc al. Early Trasnmission Dynamics un Wuhan, China, of Novel Coronavirus -Infected Pneumonia. N Engl J Med. 2020; 382(13):1199-1207. DOI: 10.1056/NEJMoa200 1316

31. Wang D, Hu B, Hu C, et al. Clinical Characteristics of 138 Hospitalized Patients With 2019 Novel Coronavirus-Infected Pneumonia in Wuhan, China. JAMA. 2020； 323(11):1061-1069. doi:10.1001/ jama.2020.1585

32. Rasmussen SA, Thompson LA. Coronavirus Disease 2019 and Children: What Pediatric Health Care Clinicians Need to Know. JAMA Pediatr. 2020; (Publicado online). doi: 10.1001/ jamapediatrics.2020.1224

33. Sociedad Española de Infectología. Actualización de conocimientos de la enfermedad COVID-19. Madrid: Sociedad Española de Infectología; 4 de abril del 2020.

34. World Health Organization. "Solidarity" clinical trial for COVID-19 treatments. Ginebra: World Health Organization; 2020. https://www.who.int/ emergencies/diseases/novel-coronavirus-2019/ global-research-on-novel-coronavirus-2019-ncov/ solidarity-clinical-trial-for-covid-19-treatments

35. Ministerio de Salud. Minsa aprueba documento técnico que establece el uso de determinados fármacos en tratamiento de personas afectadas por Covid-19. Lima: Ministerio de Salud; 31 de marzo del 2020. 